DRAFT

The Virtues of Strangers? Policing Gender Violence in Pacific Island Countries

Melissa Bull, Jodie Curth-Bibb and Nicole George

Associate Professor Melissa Bull, School of Criminology and Criminal Justice and Griffith Criminology Institute, Griffith University, Queensland, Australia.

m.bull@griffith.edu.au; School of Criminology and Criminal Justice and Griffith Criminology Institute, Griffith University, 176 Messines Ridge Rd, Mt Gravatt, QLD, Australia 4122.

Dr Jodie Curth-Bibb, School of Political Science and International Studies, University of Queensland, Australia

j.curth@uq.edu.au: POLSIS, Building 39a, Level 5, University of Queensland, St Lucia QLD, Australia 4072.

Dr Nicole George, School of Political Science and International Studies, University of Queensland, Australia

n.george2@uq.edu.au; POLSIS, Building 39a, Level 5, University of Queensland, St Lucia QLD, Australia 4072.

Corresponding author: Melissa Bull; m.bull@griffith.edu.au; School of Criminology and Criminal Justice and Griffith Criminology Institute, Griffith University, 176 Messines Ridge Rd, Mt Gravatt, Qld 4122; ph/fax (011-61) (0)7 37353328/5608. 


\title{
The Virtues of Strangers? Policing Gender Violence in Pacific Island Countries
}

\begin{abstract}
This article considers the gap between reformist policy and practice in the policing of gender violence in Pacific Island Countries (PICs) with a key focus on Solomon Islands, Fiji and Kiribati. In doing so, we critically engage with two pervasive arguments in policing scholarship: (1) arguments regarding the value of hybridity and regulatory pluralism in PICs; and (2) the dominant critique of 'policing by strangers'. We outline and acknowledge the compelling logics of these arguments but we contend that they are called into question when (re)evaluated through a gender lens. Drawing on in-country fieldwork observations, relevant reports from government and nongovernment sources, and secondary literature we begin to map out the empirical evidence that demonstrates the fragility of such positions in the case of policing gender violence. We go on to explore the complexity of institutional reform processes in PIC police forces by providing an overview of the intersection between informal operating cultures and police reform agendas - particularly as they relate to the policing of gender violence. We argue that Georg Simmel's (1950) idea of the stranger, illustrating the contradictory experience of what it means to engage with someone who is spatially close but socially distant, offers a framework for exploring policing reform in the context of gender violence. Approaching gender violence through the lens of the 'stranger' potentially supports the development of a context specific professional ethic that is able to effectively navigate conflicting forms of authority that currently undermine policing in PICs to provide better outcomes for women.
\end{abstract}

Keywords: gender violence; strangers, hybridity, police reform 


\section{Introduction}

Like many other parts of the world, high rates of gendered violence impact in negative ways on life in Pacific Island countries (PICs). A raft of recent studies conducted in Samoa, Solomon Islands, Kiribati, Fiji, Vanuatu, Tonga and New Caledonia suggest that between 40 and 70 percent of women experience violence at the hands of intimate partners and family across their lifetimes (SPC 2006, SPC 2009, SPC 2010, SPC and UNFPA 2001, FWCC 2013, Vanuatu Women's Centre and Vanuatu Statistics Office, 2011, Salomon and Hamelin 2010, Ma'a Fafine mo e Famili, 2012). These studies also show that incidents of violence are frequently severe and often see women exposed to physical and sexual assault (SPC, 2009a, 2010). In Solomon Islands, for example, nearly two in three (ever-partnered) women (aged 15-49) have experienced physical or sexual violence, or both, inflicted by their partner - with sexual violence more common than physical violence. It is also reportedly more common for women to experience severe, violence in the form of assaults with weapons, punching and kicking (SPC 2009a, p.3).

As in other societies, gender violence phenomenon has proved hard to arrest in this region. Thirty years of aid programming, civil society advocacy and scholarship has certainly raised awareness of this issue amongst the region's political elite. For example, the 2012 communique issued at the conclusion of the Pacific Island Forum (PIF) Leaders Meeting, highlighted violence against women as a key regional challenge. The communique also included a separate Declaration on Gender Equality committing member states to improve their responses to the violence epidemic (PIF 2012) and saw an AUD 320 million fund established to improve the economic and political standing and physical security of women.

Evidence that these commitments are being taken up at the national level is increasing. In 2012, the Fiji Police Force (FPF) launched a new 'Duavata' or community policing program, which nominated the elimination of violence against women as one of its central aims (FPF 2012, George 2016). In 2013, the government of Papua New Guinea passed family protection legislation that was first drafted in the early 1990s (Chandler 2014). By mid-2014, governments from Kiribati, Solomon Islands, Samoa and Tonga also passed new family safety legislation that aimed to protect women and girls from violence (SPC 2014). These legislative reforms included better legal protections for women and children aiming to leave violent family relationships, the classification of new crimes of gendered violence and stronger sentencing criteria for perpetrators of this violence.

Reform has originated as a result of local demand and externally driven interventions. In Solomon Islands, for example, it has been part of ongoing police capacity building programs undertaken by the policing contingent of the Regional Assistance Mission to the Solomon Islands (RAMSI), a long-term multilateral program designed to build state institutional capacity as the country transitions from conflict that began in 2003. The policing component of this program was known as the Participating Police Force (PPF). The PPF was instrumental in developing Family Violence and Community Policing units, as well as providing significant technical support and capacity development to the Sexual Violence Unit (RAMSI 2013). In Kiribati local reforms have been supported by a regional 'Pacific Prevention of Domestic Violence Programme’ (PPDVP), funded by the New Zealand 
Ministry of Foreign Affairs, the New Zealand Police and (since 2013) the Australian Federal Police (PPDVP 2014). ${ }^{1}$ There has been a deliberate attempt to ground this program in locally relevant narratives. Reform draws on cultural and religious sources of legitimacy and moral authority to defend the idea that improved policing in the area of spousal, or partnerperpetrated violence is consistent with localised value systems upholding strong family relationships (PPDVP 2014). This scenario, however, may mean police personnel are less inclined to view women who experience gendered forms of violence outside the familial or conjugal setting as 'real' or 'legitimate' victims of crimes that deserve their attention (Du Mont et al 2003, p.466; Salomon 2003).

This focus on family values has interesting similarities and differences with official policing policy on gender violence in Fiji, where policing programs geared to meeting the challenge of gender violence involves a community policing response that draws on local stakeholders representing customary and religious organisations. In practice, this policy is layered problematically over an existing institutional context where policing is generally of a hardline, authoritarian style and framed by government decrees, which since 2009, have stipulated a 'Zero Tolerance' approach to violence against women (George 2016). There is some evidence that this results in women facing strong pressure from customary and religious leaders in their community not to report instances of violence both because this may rupture the integrity and sanctity of their marriage, but also so that perpetrators might be spared a strongly punitive state policing response (FWCC 2013).

The differing origins of each of these programs suggests further questions might be asked about the extent to which they are locally "owned" by national police personnel. In Kiribati and Fiji programs of policing reform on gender violence have a stronger 'home-grown' orientation; although, in Kiribati particularly, they involve partnerships with organisations that are part of the international aid and development community. In Fiji, policing reform responded to demands from local women's human rights campaigners whose work, in the past, has met with suspicion if not outright hostility in some quarters, because they are often felt to represent Westernised feminist perspectives that have a poor fit with the local sociocultural context (George 2012). In short, across PICs the policing of gender violence is shaped by the interplaying values, ideas and practices that stem from the presence of international, regional, national and more localised institutions. But what are the implications of this interplay for everyday policing practice in the area of gender violence?

This layering of different institutional practice may make it difficult to translate programs of policing reform in ways that effect everyday policing operations. Police studies scholarship has shown that there is generally a vast distance between legislative agendas and policies to reform policing and evidence of change in the 'workaday micro-processes' of policing practice (Peake and Marenin 2008, p.64). This resistance is particularly pronounced in the area of gender-sensitive policing reform. Scholarly and popular literature has bitterly lamented the apparent failures of regional efforts to reform the policing of gender violence as well as the limitations of policing generally in this area (Chandler 2014, George 2016, Macintyre and Macleod 2007).

\footnotetext{
${ }^{1}$ The Australian Federal Police support this program and work in partnership with it as part of the Pacific Police Development Program - Regional, which now has a dedicated gender advisor.
} 
One standard explanation for why police reform and capacity development agendas do not translate into tangible improvements in police practice is the argument that imported models of policing (involving policing by strangers) imposed on PICs through colonial and, more recently, donor interventions are operationalised in a ways that are mis-matched to, or misread, the needs and aspirations of local communities. Proponents of this viewpoint argue that policing will be brought 'closer to the people' when it is delivered in way that better harmonises with existing sources of socio-cultural authority (Baker and Sheye 2007). 'Hybridised' models of regulatory authority may see policing operate in ways that are more attentive to prevailing cultural norms so that it 'meets local demands' and better resonates with the 'needs' of local citizens.

This article considers the gap between policy and reform agendas and the practice of policing gender violence in PICs, offering a conceptual framework for exploring this difference in the interests of improving policing outcomes on the ground. It critically engages with two pervasive ideas that shape policing scholarship focused on this region: (1) arguments regarding the value of hybridity and regulatory pluralism in PICs; and (2) the dominant critique of 'policing by strangers'. We outline and acknowledge the compelling logics of these arguments but suggest that such logic is called into question when (re)evaluated through a gender lens. We adopt an ethnographic approach to map out empirical evidence that suggests these dominant claims should be revisited. Specifically we demonstrate how claims valorising hybridised forms of regulatory authority commonly described in scholarly research are challenged by illustrative examples of how customary systems and 'familiar' police actors have failed women in the region when it comes to policing gender violence. These examples are drawn from in-country fieldwork observations in the Solomon Islands, Fiji and Kiribati. Each of these countries secured independence from British colonial interests in the 1970s. As a result, similar colonial models of administration have influenced the form of policing in each jurisdiction. While state authorities in each of these settings have committed to improving the policing of gender violence, the everyday implementation of these strategies occurs within a pluralised systems of regulatory authority shaped by custom and faith based groups as well as the presence of international policing personnel in Solomon Islands and Kiribati. The particular configurations of hybridized authority in each of these settings makes the observational comparisons we draw between these cases particularly compelling. To further contextualize our claims we make reference to relevant studies in feminist legal anthropology conducted in other Pacific island contexts notably New Caledonia, and Papua New Guinea and Bougainville. Where pertinent we draw on range of grey literature sources produced by regional intergovernmental agencies, as well as state and non-government organisations publications. We conclude by considering if, and how, policing in this area could be enhanced through improved state based systems of policing that draw on the potential strengths of 'stranger' authority and regulation.

Scholarship on international policing has shown that the presence of 'stranger' police can result in increased reporting of family violence, increased safety of women and children and increased community awareness about women's rights and safety (Van Der Spuy 2001, Harris and Goldsmith 2010, Greener 2009, Furnari 2014, Cuddy 2013). This is often as a consequence of them being viewed as outsiders. According to Mona Girgis (2007) this outsider status 'allows [police who are deployed] to transcend local norms, enabling them to question assumptions, choose to disregard systems with which their local counterparts have 
to comply and to do things that local people cannot do' (p.366). Of course, we acknowledge that while the benefits of social distance might seem straight forward in the context of peacekeeping and development missions, any interaction that involves outsider policing that simply ignores local practices is problematic. We, nevertheless, propose that the status of the stranger might offer some value, and hypothesise that Simmel's (1950) conceptualization of the stranger offers a framework for the development of a type of professional ethic that is sensitive to context in ways that could support both the ethical comportment of police deployed as part of international peacekeeping and capability interventions, and local police to be more effective in their policing responses to violence against women. In short, approaching gender violence through the lens of the stranger could inform the development of a contextually informed and contingent professional ethic as a means to navigate conflicting forms of authority that currently undermine the policing of gender violence in PICs.

\section{Perspectives on hybridity and regulatory pluralism in the Pacific Islands}

Recent scholarship has generated important insights into the social, political, economic and cultural factors which shape policing institutions in the Pacific Islands and the success or otherwise of externally driven police building programs (Harris 2010, Dinnen 2010, Dinnen and Allen 2013, Dinnen and Macleod 2009, Dinnen, Mcleod and Peake 2006, Goldsmith 2006, 2002, Greener-Barcham 2011, Kingsbury 2010, Harris and Goldsmith 2010; Hughes et al 2013). These studies have often been critical of externally driven programs of reform that are based unproblematically on Weberian assumptions about state monopolisation of the means of force in the Pacific Islands. They commonly argue that this approach fails to adequately grapple with the ways regulatory authority functions in Pacific Island societies, and the factors which may potentially constrain policing legitimacy (Greener Barcham 2011, Dinnen 2010, Dinnen and Allen 2013, Dinnen and Macleod 2009, Dinnen, Mcleod and Peake 2006). State agencies and institutions are frequently deemed to have limited relevance for many Pacific Islanders, and certainly for the majority of populations living in remote rural settings. In such contexts, informal sources of regulatory authority, customary or religious, are said to contribute to a system of 'regulatory pluralism' (Dinnen and Mcleod 2009, p.335) which may be more efficient and more capable when managing social order, and even dispensing appropriate forms of justice, than a sole reliance on state law and order mechanisms.

The concept of hybrid authority structures (an idea which has been more commonly advocated in peace and conflict studies literature on peacebuilding (Brown et al 2009)) has recently been advanced to convey the idea of 'constructive complementarity' between formal state security agencies and other informal sources of regulatory authority in Pacific Islands contexts (Dinnen and Peake 2013). A great deal of this discussion laments the opportunities lost to would-be police reformers 'who pay insufficient heed to the multiple actors involved in policing activities and dispute resolution in countries characterised by high levels of legal and normative pluralism' (Dinnen and Peake 2013, p.570). Cases where this regulatory pluralism is sufficiently recognised and even privileged are celebrated as operating productively 'with the grain of local beliefs and practices ... linking the authority of state with that of local social orders’ (Dinnen and Peake 2013, p.572). 
Those who invoke the hybridity paradigm, point to the futility of attempting to inforce statebased approaches to policing and justice which are informed by 'western' assumptions regarding norms, rights and the primacy of formal rule of law systems - without regard to existing norms and practices. To substantiate this view they explain that that the "delivery" of liberal templates of peace and state' involves 'a meeting of profoundly different lifeworlds and worldviews,[and] the collision, interaction and entanglement of different understandings of socio-political order' (Boege and Curth 2011, p. 15). Recognition of 'local strengths' is proposed as a way to navigate this type of entanglement. Brigg, Boege and Curths' research explicitly aims to 'develop collaboration among international interveners, state agencies and local actors to better prevent and manage violence and conflict by drawing upon societal practices and capacities' (2010, p.2). While this work emphasises recognising and working with local norms and processes, it also consistently demonstrates the importance of strengthening state systems as well (see also Allen et al 2013). From this perspective hybridity opens up understandings of governance and consolidated social order by asking where and how localised and top-down sources of authority can operate in effective complementarity (Brown et al 2010, 101, Mac Ginty 2008).

In contrast, more sceptical appraisals of the hybridity concept have illustrated the coconstitutive nature of the relationship between 'top-down' and 'bottom-up' sites of regulatory authority, and the extent to which more formalised entities may construct their own 'local' according to what they are able to 'find, initiate or are willing to support financially' (Heathershaw 2012, 280). Others have given close consideration to the ways localised sociocultural practices may be appropriated by particular groups to serve sectional interests potentially subverting the original aims, symbolism or meaning of that activity; a scenario which, in certain contexts, explains the increasing commercialisation of traditional gift giving as part of customary reconciliation practices for example (Wallis, Kent and Jeffery 2016). A further consideration in the debate on regulatory enforcement is that the recent hybrid turn in critical security studies analysis aligns with a global neoliberal orthodoxy. This has encouraged public sector retreat from security provision and the outsourcing of security agency work to privatised military and security companies (PMSCs) with attendant problems of accountability (Abrahamson and Williams, 2011).

Together these observations remind us that there will always be localised debate about how sites of authority are defined and understood, and whose voices are deemed to be authoritative on these questions. The work of ethnographers such as Nicholas Thomas, Ton Otto, Margaret Jolly and Brownen Douglas (see edited volume by Thomas and Otto 1997), as well as political analysis by the likes of Stephanie Lawson (1996) or Stewart Firth (1997) has laid bare how ideas about 'culture' or tradition in Pacific Island societies have been constituted through processes of local and national contestation. It highlights complex interplays with the external and globalising influences of colonisation, missionisation, and in more recent times, economic globalisation and neoliberalism. Importantly, this work demonstrates how articulations of local customary or religious authority are shaped by social and economic relations of power. It reminds us that particular groups in society may receive particular sorts of benefits when regulatory authority is hybridised in ways that serve their interests. 
In this article, we argue that this is a profoundly important question to pose when seeking to understand how hybrid systems of regulatory authority in PICs respond to cases where women are exposed to gendered violence. Debates on hybridity have not always reflected, as fully as they might, on the way potentially discriminatory relations of gendered power shape the functioning of sites of 'local strength'. As we show in this next section, this proposition, is supported, by findings from research conducted with women across the region on the ways gender violence is subject to regulation (or not) in their societies.

\section{Hybridity and the regulation of gender violence in practice}

Feminist enquiry into the difficulties Pacific women face in securing justice when they are the victims of gendered crimes frequently point to the gendered failings of state and customary systems of justice, finding that both systems reflect and further entrench the subordinated status of women. But it is also important to understand the ways that interplays between these orders presently sustain gendered discriminations that may make justice elusive for women exposed to gendered violence in these contexts.

Customary approaches to dispute settlement in the Pacific Island countries tend to involve public meetings, known regionally as 'custom courts', where complainants present their grievances against alleged offenders before the community. The matter is then deliberated upon publically and local tribal chiefs or elders come to a consensus about the validity of the complaint and an appropriate form of customary punishment. While these types of dispute mediation processes generally enjoy strong support from local populations for particular sorts of (communal level, and minor) disputes (Boege 2010, Forsyth 2011), the legitimacy of customary justice may be questioned in contexts where chiefs no longer command the same levels of respect and deference they were accorded in the past (a particular phenomenon in Melanesian contexts where violent conflict has occurred such as Bougainville (George 2016)). Power-holders in the community, typically older men, tend to dominate the decisionmaking processes in these forums and the participation of women and youth can be limited. This works against the interests of women who pursue complaints of gendered violence in customary courts and are made to feel that "they are not free to talk or "their word is not good enough” (Garap 2000, p.163).

A range of academic and activist sources have shown how religious sources of authority can function in ways that discourage women from making complaints of gendered violence public or taking them to state authorities. In many Pacific Islands contexts, church leaders may be the first figures of authority outside the familial setting that women contact when seeking advice about their personal exposure to violence. But religious leaders often tend to offer advice that is informed by a conservative religious doctrine, which celebrates feminine docility and obedience and the continuity of marital vows. Even in contexts where they suffer repeated exposure to conjugal violence women may be advised by religious (usually Christian leaders) to 'suffer' this violence with Christian forebearance, rather than to look for a means of escape (George 2015, Hermkens 2011, Meo 2003).

For these reasons state systems of justice are commonly nominated by gender advocates as more effective sources of justice for women who endure gendered violence. This does not mean that that the value of custom or faith-based regulation is completely dismissed. The work of legal anthropologist Sally Engle Merry has shown how gender activists articulate 
claims upholding women's rights to secure violence-free lives with longstanding cultural or religious discourses that stipulate respect for women, or uphold matrilineal authority (Merry 2006). While these rights 'translation' processes have been observed in the advocacy of gender activists in a number of Pacific Island contexts, and often described as indicative of political resourcefulness and creativity (Jolly 1997, Monson 2013, George 2015), it has been argued that in contexts where indigenous nationalism is particularly potent, gender activists may find this strategy constraining, and can lament the fact that they are conceding too much territory to parochial masculine elites (George 2012, Hermkens 2012).

The view that state systems of justice are more effective sources of justice for women who endure gendered violence seems also to be shared more widely amongst the general populations of Pacific Island countries when the circumstances of women exposed to serious incidents of sexualised violence is discussed (Forsyth 2011, 125; see also Zorn 2011, 2010; Salomon 2003). In Solomon Islands, women have argued that 'excessively violent attacks' should 'be reported to police' if there is certainty that police 'would do something about it' (Brigg et al 2010, p.4). Similar opinions are held by that country's Permanent Secretary for Ministry of Women, Youth and Children Affairs, who, although supportive of programs that acknowledge local strengths, is critical of the idea that these approaches are equally meaningful for everyone. In particular she noted that when a girl is raped, reconciliation is about peace between tribes (Hughes et al 2013, 232), or focussed on the defendant making amends to the broader community. Consideration for the complainant's personal circumstances may become secondary to these broader restorative goals (Forsyth 2011, pp. 178-9).

Nevertheless, we need also to critically assess the claim that state policing or judicial agencies have a greater capacity to deliver justice for women victims of violence. Indeed feminist legal anthropology in the region suggests that state judicial mechanisms frequently adjudicate cases of violence against women in ways that also reflect high levels of gendered discrimination. Jean Zorn shows for example, that even while court judges in PNG may consider rape a serious and too prevalent crime, they tend to preside over trials in ways which reflect discriminatory views. Hence their rulings often reinforce doubts about the credibility of women complainants' testimony or the idea that women invite abuse when their behaviour contravenes widely accepted norms of gendered virtue and respectability (Zorn 2010, p.17).

Our own work has shown observations of state policing authority, in other Pacific jurisdictions may operate in ways which is strongly intertwined with religious and indigenous sites of authority, undermining the protections that can be offered to women in situations of violence (George 2016). For example Fiji's 'zero tolerance' policing strategy, (referred to on page 1) was designed to reduce the incidence of violence against women while also working with community and religious leaders who are charged with responsibilities for gender violence prevention. While reduced gender violence crime statistics are celebrated by Fiji's governments, women activists raise concerns. On the one hand, they contend that the involvement of local leaders in prevention activities often sees pressure placed on women to endure violence in the home rather than break marital vows (FWCC 2013). On the other hand, a gross under-reporting of incidents of gender violence to authorities is said to have ensued because villages who declare themselves 'violence free' are eager to maintain their positive profile with state authorities, and have become fearful of unwanted and highly 
punitive police scrutiny (Ali 2013). While this hybridised model of regulatory authority may indeed incorporate local strengths at some level, it does not seem to offer a system of justice that effectively enables women to seek redress for, or protection from, the violence they may suffer in family and community life.

Taken together these scenarios make clear that, when viewed through a gendered lens, the much repeated call for more "complementarity" between customary and state systems of justice may be redundant. Our contention is that systems of hybridised justice, at least as they pertain to the regulation of gendered crimes, already exist in many Pacific Island jurisdictions; however, they do not serve the interests of women exposed to violence as well as they might. We therefore suggest that it is important to turn the investigative lens more squarely on the reasons why the distance and presumed 'impartiality' of state authority is important. For women who seek to have the incidents of gender violence they have experienced recognised as crimes, we believe this impartiality and potential distance is particularly valuable. As we have shown, hybrid systems of justice, which recognise the legitimacy of customary approaches to justice, can elevate informal systems of authority to the point that they undercut, or undermine, the potential strengths of state-based approaches. The example of Fiji, described above is, particularly pertinent in this regard, as are reports from women victims of gendered violence who express disappointment in the justice outcomes delivered to them by more proximate customary or village authorities (see Salomon 2003, 2000). This ultimately leads us to consider the value of policing by strangers from a gender perspective, a theme we take up in the section below.

\section{Policing by strangers}

As an offshoot of their interest in understanding the place that formalised policing holds within hybridised systems of regulatory authority, studies of policing in the Pacific Islands have argued that the capacities of institutionalised police forces are compromised because Pacific Island populations generally view state-based systems of authority as a 'distant presence' with an 'uncertain relevance' (White 2007, p.6). This argument has also been replicated in research assessing police-building programs involving the deployment of international police units from neighbouring countries (Australia or New Zealand) (although not always see Dinnen and Peake 2013).

Post-colonial policing scholars rightly highlight the potential for reform programs supported by international interventions to reproduce power relations resembling past forms of colonial domination. Such criticisms are often justified in the realm of what Brodeur $(1983,2010)$ refers to as 'high policing' concerned with securing the interests of the state and political elites (Bowling and Sheptyki 2012, p.16). They may be less convincing, however, in the context of 'low policing' - the array of roles, functions and work routines addressing the maintenance of a safe population - and gender violence in deployment settings. While a significant proportion of the population in PICs has little experience of state-centred policing because of its limited reach (White 2007), scholarship on international deployment has nevertheless shown that the presence of 'stranger' police can result in increased reporting of family violence, increased safety of women and children, and increased community awareness about women's rights and safety (Van der Spuy 2011, Harris and Goldsmith 2010, Greener 2009, Furnari 2014, Cuddy 2013). 
Taking this point of departure we conceptualise policing by strangers in a new and innovative way by drawing on Georg Simmel's (1950) description of strangers as a member of a group in a spatial sense, but still not a member in a social sense; a person who may be in the group but not of it (1950, pp.402-3). This is not the same as Park's (1928) marginal man who is usually identified with the outsider who has just arrived in a certain group: a racial or cultural hybrid who has no status of equal membership although he wants it. Simmel's stranger does not want to be assimilated. Nor is it Schutz's (1944) newcomer: a guest or visitor who fights to be socially accepted, or at least tolerated by the group. While these, and other social types subsequently developed (Bauman 1995, Sui 1952, Stonequest 1937, Wood 1934), were undeniably inspired by Simmel's work, Simmel's figure of the stranger has some important differences. Primarily, Simmel's stranger synthesises elements of proximity and distance. The stranger is a social type that is able to adopt a perspective that is simultaneously that of an insider and an outsider; this involves the meeting of life worlds (Diken 1998).

This conceptualisation draws on Simmel's sociology of space, which underlines the importance of social distance (Skoric et al 2013). Distance, which includes both remoteness and proximity, closeness and distance, is a basic feature of human life, because spatial and temporal gaps indicate that we are always in a state of 'being in between'. Simmel's analysis of distance and movement emphasises that social life is not composed of static structures. His excursus on the stranger builds on this work by focusing on space rather than culture.

Simmel's account of the stranger does not refer to a fixed identity or categorical difference; rather the stranger is constituted through relationships that mediate remoteness and proximity. These relationships are socially constructed and hence, dynamic and changeable. This is useful because it allows us to avoid essentialism, and the (common) reductive tendency to understand the concept of the stranger simply in terms of static characteristics that are often portrayed as mutually exclusive social differences arising from membership of particular social, ethnic or cultural categories or groups. From this perspective it is possible for the same person to navigate relationships characterised by closeness and distance as social contexts require.

In Simmel's analysis distance is not opposed to proximity, nor does it represent a negative condition. It gives the stranger capacities like mobility and objectivity. The stranger is a mobile type that comes incidentally into contact with every single element of the group, but is not bound up organically, through established ties of kinship, locality or occupation, with any single one. The stranger's 'objective' attitude with regard to social issues is possible because $\mathrm{s}$ /he is simultaneously included in the life of the group, and is somewhat indifferent towards the events of the group. Not bound by roots to the particular constituents and dispositions of the group, the stranger is able to be more 'objective'. Here 'objective' refers to 'an attitude that does not signify mere detachment and non-participation, but is a distinct structure composed of remoteness and nearness, indifference and involvement' (Simmel 1971, p.145).

According to Simmel, strangers often carry out special tasks that no one else in the group is capable of, or willing to, perform. The stranger has virtue as an arbitrator, for example, because s/he has something in common with both groups and forms a kind of reference point with respect to them: 'what is common to both parties (the basis, that is, of their conflict as well of their possible reconciliation) must somehow be inherent in the arbitrator, or must at least be accessible to him' (Simmel 1950, p.221). As Karakayli (2006) explains, while the 
arbitrator is uncommitted to any group of contestants s/he is not a stranger to the system of beliefs or standards that control the situations in which s/he is called upon to operate. This might be as a servant of power, as in the post-colonial critiques. Nevertheless, at the same time, the stranger is among other things, more likely to be accepted as a confidant; and enjoys greater freedom from convention and is not restricted in his or her actions by '... habit, piety and precedent' (Simmel 1950, p.405). This offers scope for the investigation of the potential for 'strangers' to go against the grain of local custom or belief. Simmel's observations suggest that the stranger figure may have particular authoritative and investigative capacities that benefit their roles as regulators of social order, and particularly crimes of gendered violence. This idea problematises claims that the legitimacy and capacity of institutionalised police forces are compromised because they are considered a 'distant presence' with an 'uncertain relevance' in many Pacific Island contexts (White 2007, p.6). Indeed, it may be that in some contexts, such distance and uncertainty are virtues.

In some Pacific Island contexts there is demonstrated ambivalence towards, or alienation from, formal policing authority. Amongst Kanak populations in New Caledonia, for example, the presence of the gendarmerie is sometimes rejected as an imposed system of 'colonial justice' or 'justice des blancs', and police officers have become the targets of light arms attacks in recent years (Nouvelles Caledoniennes 25 January 2015, p.1). But preliminary enquiries on this theme in New Caledonia have revealed that in even within Kanak society, rejection of the 'stranger figure' of state, or even international policing authority, is not universal. Sometimes the extent of challenges to social order, such as those posed by youth crime, are such that local customary leaders feel overwhelmed, and counsel those who seek their intervention to approach the local gendarmerie for assistance (reported in discussions with Kanak women, personal communications, January 2015).

Curth-Bibb’s (2010) research on capacity development approaches in Solomon Islands found that local women police officers were able to strategically navigate the type of dynamic Simmel describes between proximity and distance by drawing on the strengths of their local culture and networks on the one hand, and on the neutrality, resources and oversight of the intervening force on the other. For example, one local police officer reported a case where a close family member had sexually assaulted another member of the family. This officer explained how she was able to mobilise her 'wantok' connections in tracking down this suspect, and implore the offender to surrender. Once in custody, however, the officer deliberately turned the suspect over to international police in order to bring in the authority and neutrality of the 'stranger', relieving her of family and cultural pressures. Further, the officer then sat down with her family and the international police advisers, and counselled them on her police role, and why it was necessary for her to take police action (personal communication, June 2010, see also Allen et al, 2013).

This evidence suggests the need for more critical enquiry into the claim that Pacific Island populations generally have greater respect for, and obedience to, local and proximate sources of religious and customary authority. Or at the very least, to critically engage with the assumption that Pacific Islanders always prefer regulatory outcomes that extend from these sources. We propose that in certain contexts the stranger figure of state, or international police may be perceived as having a particular effectiveness or objectivity that is valuable in 
the regulation of certain kinds of threats to social order; and perhaps most particularly, crimes of gendered violence.

While we are interested in the capacities of the 'stranger' figure, we are also conscious that in some policing jurisdictions the lines that distinguish the stranger from the local, are not always easy to discern. In other places they arguably may not exist at all. In this regard, we are particularly interested to examine how the gender prejudicial ideas, which may circulate more generally in Pacific Island societies, influence the conduct of formalised police forces when it comes to the policing of gender violence. We are also interested in understanding the contextual nuances regarding when police are considered to be 'strangers', and when they are considered to be familiar or local. That is to say, under what circumstance will a police officer be understood (by members of the community and women in particular) to be part of, and subject to, broader social norms and rules (including customary and religious interpretations), rather than an independent actor operating impartially according to the formal rule of law? In this regard, it is important to critically examine the presumption that institutionalised police forces demonstrate a unique approach to the challenge of gender violence that automatically makes them 'strangers' in their jurisdictions, a question we consider in more detail in the section below.

\section{Informal operating cultures and police reform}

Whether or not police officers are indeed 'strangers' in these different contexts is a question that requires us to consider how informal operating cultures that are manifest within state policing agencies impact upon police activity, behavior and reform processes. Studies in the area of Pacific Islands police-building have underscored the fact policing institutions are not simply monolithic and passive entities which are acted upon (by local reformers or donor interventions). Rather they are conceptualised as institutions made up of a range of differently situated actors who may variously ignore, accept, re-interpret or resist, directives received from those in higher positions of authority. In the Pacific Island context the distances and poor communications that exist between police headquarters and outlying or remote police posts compound this situation. In these contexts 'operational cultures' amongst police personnel may be less strongly informed by (coupled with) the formal legal regimes developed by policy communities in capital cities, and more strongly informed by (coupled with) the cultural and religious adherences of police personnel (Peake and Marenin 2008, p.64). Reforms may be undone or resisted by an 'informal operational culture' that may distort or pose an outright challenge to official programs aiming to transform police operations (Peake and Marenin 2008, p.64).

The international literature on the policing of violence against women has shown how commitments to gender reform in policing are challenged by informal operational cultures. This literature notes that police officers' capacity to understand and assess a gender violence scenario is frequently shaped by broadly held social prejudices that may be generally gender discriminatory, or discriminatory to particular groups (Gover 2011, see also Trujillo and Ross 2008, De Jong et al 2008). Relevant here are questions about how these prejudices shape police officers views on what constitutes a 'real' or 'genuine' victim; with the status of recognised victim often denied to those who claim to have experienced violence, but have their accusations downplayed, or disregarded, because of their background as sex workers, low income women, or perhaps simply as indigenous women (Du Mont et al 2003, p.466; 
Salomon 2003). In this way there appear to be degrees to which formal police are, and behave as, 'strangers' in different contexts. As we have shown in earlier parts of the discussion, state policing in Fiji is powerfully shaped by intertwined religious and customary values systems. This may make police appear to the local population less like strangers, but it does little to ensure women victims of violence will receive their protection. In some contexts entrenched norms, or quietly accepted behaviours of this type, may be so powerful that they blur the lines between the police and the policed. Research conducted by ethnographers working within the PNG constabulary has argued that members of this force are highly likely to be perpetrators of gender violence in their own conjugal relationships (MacIntyre 2009, Macintyre and McLeod 2007). They are frequently also accused of perpetrating violence against women in the course of their professional duties, or when women approach them for protection from other sources of violence (MacIntyre 2009, Macintyre and McLeod 2007, Chandler 2014). On the other hand, there are instances where the religious and social norms of police and their actions as perpetrators of domestic violence are addressed as part of more general reform efforts. A gender violence program operating in Kiribati, for example, engages directly with the issue of police as perpetrators. It works with cultural and religious authorities to challenge the acceptance of gender violence in a self critical way by promoting the rule of law using slogans such as 'culture is no excuse for abuse', 'religion is no excuse for abuse' (Ronald 2015).

Social norms, culture and religion are also known to shape informal operational cultures in regards to the standing of women police officers and their role in policing gender violence. Within the international literature on violence against women there has been interest in understanding the impact of growing numbers of women in institutionalised policing and how this might create a more sympathetic, and less gender prejudicial, policing response to complainants in gender violence cases (De Jong 2004, Chu and Sun 2007). An international review of the status of women police officers reported that in 2011 in Fiji women made up 20 percent of recruits (Prenzler and Sinclair 2013), and according to the Solomon Island Police Force Annual Report 2014-5 women were 17 percent of the force. We could not find any data describing the gender composition of the Kiribatti Police Service. According to Prenzler and Sinclair (2013) while lower rates of female participation in policing might be expected in emerging democracies and developing countries, where there are often strong legacies of male domination and limited capacity to enforce equity legislation, rates reported for countries like Fiji were often well ahead of those in developed countries like the United States (11.8) and New Zealand (17.6). Indeed, across the 23 locations they studied the rate of female participation in policing appeared to have plateaued, and even in countries with favourable recruitment strategies it did not exceed 28.8 percent. Prenzler and Sinclair (2013) concluded that at the international level there was very little evidence that United Nations' policies or agreements on women's employment or the protection of women from crime (e.g. UNDP 2007) translated into practice within police departments.

Nevertheless, in some contexts the introduction of women police and formation of specialised squads, or women's police stations dedicated to the policing of violence against women or sexual violence has been hailed as a progressive development (Cole and Phillips 2008, Du Mont et al 2003). The benefits of these approaches, however, are yet to be conclusively proven, and there exists a number of alarming trends in this area of policing which are arguably the product of informal institutional cultures. For example, it has been suggested 
that women officers may emulate the masculinised norms that pervade police forces generally, and thus police gender violence cases in ways no different to their male colleagues (Parsons and Jesilow 2000). Macintyre's (2012) work with women police officers in PNG supports this point, and shows that women officers were also likely to see violence as an acceptable means of settling disputes with other women, in matters where, for example, those women are deemed to pose a personal threat to their marriage or their family integrity. Such observations suggest that local police, and women officers in particular, exist in an ambivalent state: on a daily basis they must navigate the tension between gender, their personal relationship to custom and/or religion and their professional commitment to the rule of law ${ }^{2}$.

It is here that Simmel's concept of the stranger comes to the fore. Simmel highlights the ambivalent condition of simultaneously being both an insider and outsider (Diken 1998), at the same time close but socially distant. This insider/outsider focus offers a framework for thinking about how police (whether they are part of the local contingent or a member of an international deployment) can be effective in the context of gender violence. The virtue of the stranger status attributed to police who come from external jurisdictions is much the same as that described by Dinnen and Briathwaite (2009) in relation to the colonial kiaps, magistrates and other expatriate officials in the context of PNG. Historically they exercised considerable autonomy in their dealings with local leaders precisely because they were foreigners. Their apparent lack of interest in competing with local populations by engaging in their politics, or being embroiled by the intricacies of wantokism, contributed to an aura of independence and impartiality. If and how local police, operating in a contemporary context, can be understood, similarly, as strangers requires deeper investigation.

Stichweh (1997, p.6) describes the stranger as a social classification that is multivalued and may be characterised by transition zones and ambiguities. He problematises the position of the stranger pointing to the ambiguity involved in the very act of attributing the status of the stranger itself. For example, the wife who marries into the family of her husband can be considered a stranger, the same may be true for a relative who lives in another house (and in comparison the wife at the same time loses the status), or for the other residents of the village who are not related, at the end of this sequence is the stranger who comes from elsewhere, and is completely unknown. The concept of the stranger in many societies regulates relations of inclusion and exclusion on many levels at the same time. It depends on minimal differences of a situational or contextual nature if someone is attributed to a we-group, or the status of a stranger, and these attributions are variable. In short, the concept of the stranger is relational (Skoric et al 2013).

\footnotetext{
${ }^{2}$ The role of women in policing gender violence is complex. It is shaped by informal operating cultures and broader social, cultural and religious norms about the appropriate role and behaviour of women. For example, McLeod's (2007) work with police in PNG identifies problems experienced by women police officers whereby they have become the target of broader social resentment regarding the changing role of women in society. This research also describes how women's advancement in the PNG police force is undermined by husbands preventing their wives from engaging in work related travel and cases where women police officers have been punished for career achievements (Curth and Evans, 2011). Curth-Bibb’s (2010) research with Solomon Islands police identified similar gendered expectations and barriers for women police officers. A full appreciation of the layered interrelationships between gender, stranger policing and forms of authority, requires more research and is beyond the scope of this paper.
} 
Constituting the stranger in this way acknowledges that space can be understood both as a physical site and also a repository of social and political relations: always under construction and never therefore closed to novel possibilities (Bjorkdahl and Selimovic 2015). Someone can always become a stranger by entering into a particular relationship with a group. Furthermore, the distance of the stranger is always contextual because it can be understood only through the things that constitute proximity among members of a group. The significance of context is clearly evident when we consider police who are members of international missions deployed to assist with peacekeeping and capacity building. When working alongside local police they can share an insider status with local law enforcement personnel through their policing role, at the same time they remain forever outsiders. In contrast local police have the dual status of insider as members of the population, and outsiders because they are police.

This tension between insider and outsider, proximity and distance, is not something that should be resolved. The social category of stranger has potentially both destructive and constructive consequences, because the stranger offers different patterns of thought, and may open a door for social change (Skoric et al 2013). Our analysis above highlights the virtues of strangers in policing gender violence. Taking this into account we argue that by embracing this ambiguity, or tension, it may be possible to develop new frameworks for policing gender violence. The example above which cites the actions of a female police officer who resolved a case of gender violence in the Solomon Islands (Curth-Bibb 2014) by navigating the dynamic between social proximity and distance, suggests that police may be able to develop professional practices that help them to similarly navigate complex relationships with local victims and offenders to achieve better outcomes in the context of gender violence.

Alternatively, the gender violence program (described above) delivered by police to police in Kiribati, demonstrates a similar style of reflexivity by relying on cultural and religious authorities to neutralise local 'culture' and 'religion' and valorise the legitimacy of state based rule of law, when challenging informal cultures of violence against women evident within the service.

We can imagine that such a proposition is viable in the context of the constitution of the professional persona of police officer if we consider Jeffrey Minson's (1997) work on the ethical comportment of experts. Minson suggests that by invoking the sense of the 'multiplex' and discontinuous character of personhood implied by Foucault's (1984) concept of pluralite 'd'ego it is possible to recognise that the same individual can in some circumstances acquire the habits of thinking and capacities for being affected which are appropriate to apparently conflicting ways of comporting oneself. In other words it is possible to describe experts as amalgams of institutionalised types of ethical character or persona, no less than as bearers of technical knowledge and the terminals of formal institutional roles and statuses' (Minson 1997:407). From this perspective it is possible for (expert) police to retain views consistent with religious and cultural beliefs, at the same time as they uphold professional ethical standards dictated through the rule of law. But such an ethic, as alluded to above would necessarily be one that was contextually informed, and feature aspects that might be situationally negotiated. We suggest that the ambiguity inherent in Simmel's account of the stranger that accommodates both proximity and distance, could be invoked in the development of a framework that can navigate hybridity according to situational and contextual demands, to assess when the distance and presumed impartiality of a state-centred 
response is warranted or not. This is not a quick and easy fix. The institutional conditions that could support the constitution of this type of professional ethic warrant much more research.

\section{Conclusion}

The purpose of this article was to consider the gap between policy and reform agendas and the practice of policing gender violence in PICs and outline a conceptual framework for exploring this difference in the interests of improving policing outcomes on the ground. In doing so it addressed two pervasive arguments in policing scholarship. First, it examined claims regarding the value of hybridity and regulatory pluralism in PICs, and in doing so it challenged dominant critiques of policing by strangers. We surveyed key claims of scholarship that is critical of externally driven programs of policing reform that are based on Weberian assumptions about state's monopolisation of the means of force in the Pacific Islands. While much of this work focuses on the benefits of hybridised structures of regulatory authority, it also draws our attention to both conceptual and pragmatic challenges associated with the ways that we think about state building and the exercise of state authority, and how it can be effectively operationalized (through policing or Rule of Law) in locations that many have long histories of fragmented sovereignty (Hansen and Stepputat 2006)

Our analysis suggested that current regulatory approaches often fail to adequately protect women from violence, and while some women prefer to use informal justice systems because they were more culturally relevant and had greater levels of legitimacy - often these systems are used in the case of serious threats to safety because they are the only option available. Indeed there is evidence that the presence of police deployed as part of capacity building and stabilisation missions can result in increased reporting of family violence, increased safety of women and children and increased community awareness about women's rights and safety.

We suggest that one way to square this tension between the apparent limits of the state centred models of policing and the short falls of hybridised structures of regulatory authority is to rethink the concept of policing by strangers, shifting it from the wholly negative formulations of this idea that are commonly associated with forms of colonial and postcolonial domination. Here we drew on Georg Simmel's description of strangers. Simmel used the stranger to illustrate a contradictory experience about what it means to engage in an interaction with someone who is spatially close and socially distant. For him the stranger is a social type that is able to adopt a perspective that is simultaneously that of an insider and an outsider, a type that is defined in terms of space, rather than an (exclusive) identity determined by membership of particular social or cultural group. Strangers are characterised by types of social distance that can be mediated according to context; someone can become a stranger by entering into a particular relationship with the group. Strangers can be destructive and constructive because they offer different patterns of thought and possibilities for social change. Recognising these possibilities we hypothesise that the concept of the stranger offers a vehicle for reimagining policing reform. We acknowledge that future work from this perspective would need to pay much more attention to the extent to which gender norms, embodied in informal rules and institutional legacies, might complicate or compromise the conceptual framework we propose. Nevertheless, Simmel's (gendered) stranger offers a new take on police deployed as part of international stabilisation and peacekeeping missions and their role in the addressing gender violence. It also suggests a framework that could positively enable state centred policing of gender violence, and the development of a gender 
DRAFT

supportive context specific professional ethic, even in systems characterised by regulatory hybridity. Of course to fully test our hypothesis much more research needs to be done. 
DRAFT

\section{References}

Ali, S., 2013. Fiji should not bank on zero tolerance reporting [online]. Fiji Broadcasting Commission, 11 December 2013. Available from: http:/www.fbc.com.fj/fiji/16126/fijishould-not-bank-on-zero-reporting-fwcc [Accessed 15 January 2015].

Bauman, Z., 1995. Making and Unmaking of Strangers. Thesis Eleven, 43:1-16.

Boege, V., and Curth, J., 2011. Grounding the Responsibility to Protect: Working with local strengths for peace and conflict prevention in Solomon Islands. International Studies Association Asia Pacific Conference, Brisbane, 29-30 September 2011.

Brigg, M., Boege,V., and Curth, J., 2010. Working with Local Strengths: Supporting States and Interveners to Institutionalise the Responsibility to Protect - Field Research Report. University of Queensland.

Bowling, B., and Sheptyki, J., 2012, Global Policing, London UK: Sage.

Brodeur, J.P., 1983. 'High Policing and Low Policing: Remarks about the Policing of Political Activities.’ Social Problems 30:507-520.

Brodeur, J.P., 2010. The Policing Web. Oxford University Press.

Chandler, J., 2014. Violence Against Women In PNG: How Men are Getting Away With Murder. Sydney: Lowy Institute for International Policy, August.

Chu, D., and Sun, I.Y., 2007. Female Police Officers' Job-related Attitudes: A comparative study of Taiwan and United States. Women and Criminal Justice. 18 (1-2), pp 107-130.

Cole, S., and Phillips, L. 2008. The Violence Against Women Campaigns in Latin America: New Feminist Alliances. Feminist Criminology. 3(2), pp 145-168.

Cuddy, S., 2013. Gender, security and development: a Bougainville case study: A thesis presented I partial fulfillment of the requirements for the degree of Master of Philosophy in Development Studies at Massey University, Palmerston North.

Curth-Bibb, J., 2014. Policing for development outcomes: complexity in program management and monitoring and evaluation. Unpublished thesis. University of Queensland.

Curth, J., and Evans, S., 2011. 'Monitoring \& Evaluation in Police Capacity Building Operations: Women as Uniform?,' Police Practice \& Research.

DeJong, C., 2004. Gender differences in officer attitude and behaviour: Providing comfort to citizens. Women and Criminal Justice. 15, pp. 1-32.

DeJong, C., Burgess-Proctor, A., \& Elis, L. (2008). Police officer perceptions of intimate partner violence: An analysis of observational data. Violence and victims, 23(6), 683-696.

Diken, B., 1998. Strangers, Ambivalence and Social Theory. Ashgate: Aldershot. 
Dinnen, S., 2010. From Ideas to Reality in International Rule of Law Work - The case of Papua New Guinea. Journal of International Peacekeeping, 14, 301-329.

Dinnen, S. and Allen, M., 2013. Paradoxes of postcolonial police-building: Solomon Islands. Policing and Society, 23 (2) 222-242.

Dinnen, S. and Braithwaite, J., 2009. Reinventing policing through the prism of the colonial kiap, Policing and Society: An International Journal of Research and Policy, 19(2): 161-173.

Dinnen, S. and McLeod, A., 2009. Policing Melanesia - International Expectations and Local Realities. Policing Society, 19 (4) 333-353.

Dinnen, S. and Peake, G., 2013. More than Just Policing: Police Reform in Post Conflict Bougainville. International Peacekeeping, 20 (5) 570-584.

Du Mont, J., Miller, K. and Myhr, T.L., 2003. The Role of 'Real' Rape and 'Real' Victim Stereotypes in the Police Reporting Practices of Sexually Assaulted Women. Violence Against Women, 9 (4) 466-486.

Foucault, M., 1984. What is an author? in Paul Rabinow (ed.), The Foucault Reader, Harmondsworth: Penguin, 101-20.

FPF (Fiji Police Force), 2013. Fiji Police Duavata Community Policing Model. Suva: FPF.

FWCC (Fiji Women's Crisis Centre), 2013. Somebody’s Life, Everybody’s Business:

National Research on Women's Health and Life Experiences in Fiji (2010/2011). Suva: FWCC.

Furnari, E., 2014. Understanding effectiveness in peacekeeping operations: Exploring the perspectives of frontline peacekeepers, University of Otago.

George, N., 2012. Situating Women: Gender Politics and Circumstance in Fiji. Canberra: ANU Press.

George, N., 2015bc. Starting With a Prayer: Gender Faith and Peacebuilding, Oceania, 78 (1).

George, N., 2016. Hybridity and Regulatory Authority in Fiji: Vernacular Perspectives on Gender and Security. In M. Forsyth et al. Hybridity in Peacebuilding and Development: Critical Conversations. ANU Press (forthcoming)

Goldsmith, A., 2002. Policing Weak States: Citizen Safety and State Responsibility. Policing and Society, 13 (1) 3-21.

Gover, A., 2011. Law Enforcement Officers Attitudes About Domestic Violence. Violence Against Women, 15 (5) 619-636.

Greener, B., 2009. UNPOL: UN police as peacekeepers, Policing and Society, 19(2), 106-118 
Girgis, M., 2007, The Capacity Building Paradox: Using friendship to build capacity in the south, Development in Practice, 17(3) 353-366

Harris, V. and Goldsmith, A., 2010. Gendering Transnational Policing Experiences:

Australian Women in International Policing Operations. International Peacekeeping, 17 (2) 292-306.

Hermkens, A., 2011. Mary, Motherhood and Nation: Religion and gender ideology in Bougainville's Secessionist warfare. Intersections: Gender and Sexuality in Asia and the Pacific, 25. Available from: http:/intersections.anu.edu.au/issue25/hermkens.htm. [Accessed 18 December, 2014].

Hughes, B., Hunt, C., and Curth-Bibb, J., 2013. Forging New Conventional Wisdom - Beyond International Policing: Learning from Complex Political Realities. Boston: Brill.

Jolly, M., 2005. Beyond the Horizon? Nationalisms, Feminisms and Globalization in the Pacific. Ethnohistory, 52 (1) 138-66.

Karakaylai, N., 2006. The Uses of the Stranger: Circulations, Arbitration, Secrecy, and Dirt, Sociological Theory, 24(4) 312-330.

Lateef, S., 1990. 'Rule by the Danda: domestic violence among Indo-Fijians,' Pacific Studies, 13(3): 43-62.

Ma’a Affine mo e Famili, 2012. National Study on Domestic Violence Against Women in Tonga. Nuku’alofa: Ma’am Affine mo e Famili.

Macintyre, M., 2012. 'Gender Violence in Melanesia and the Problem of Millennium Development Goal No.3’. In: M. Jolly and C. Stewart, eds. Engendering Violence in Papua New Guinea. Canberra: ANU Press.

Macintyre, M. and Mcleod, A., 2007. The Royal Papua New Guinea Constabulary. In: S. Dinnen and V Luker, eds. Civic Insecurity: Law, Order and HIV in Papua New Guinea. Canberra: ANU Press.

McKenzie Aucoin, P., 1990. 'Domestic violence and social relations of conflict in Fiji,' Pacific Studies, 13(3): 23-41.

McLeod, A. 2007. Police reform in Papua New Guinea. In A. Brown (Ed.), Security and development in the Pacific Islands: Social resilience in emerging states. Boulder, CO: Lynne Rienner.

Meo, I., 2003. Asserting Women's Dignity in a Patriarchal World. In: L. Johnson and J. Filemoni- Taefaeono, eds. Weavings: Women Doing Theology in Oceania. Suva: Institute of Pacific Studies. 150-160

Minson, J., 1997. 'What is an expert?' in C. O'Farrell (ed.), Foucault: The legacy, Brisbane: Queensland University of Technology, 405-17. 
Nelson, S., 1996. Constructing and Negotiating Gender in Women's Police Stations in Brazil. Latin American Perspectives, 23 (1) 131-148.

Newland, L., 2012. New Methodism and Old: Churches, Police and State in Fiji, 2008-09. The Round Table, 101(6), 537-555.

Nouvelle Caledoniennes. 2015. Un crime qui se répète. Les Nouvelle Caledoniennes, 25 Janvier, p.1

Panchanadeswaran, S., and Koverola, C., 2005. The Voices of Battered Women in India. Violence Against Women, 11 (6), 736-758.

Park, R.E., 1928. 'Human migration and the marginal man', The American Journal of Sociology, 33(6): 881-893.

Parsons, D. and P. Jesilow. (2001). In the same voice: Women and men in law enforcement. Santa Ana, CA: Seven Locks Press.

Peake, G. and Marenin, O., 2008. Their Reports are Not Read and their Recommendations are Resisted: the Challenge of the International Police Policy Community. Police Practice and Research: An International Journal, 9 (1) 59-61.

PIF (Pacific Islands Forum), 2012. '43 Pacific Island Forum Communique'. Available from: http:/www.abc.net.au/news/2012-08-31/an-forum-communique/4237098. [Accessed 6 May 2015]

Prenzler, T. and Sinclair, G. 2013. The status of women police officers: an international review, International Journal of Law Crime and Justice, 41(2) pp. 115-131.

Ronald, C., 2015. Pacific Prevention of Domestic Violence Programme (PPDVP). New Zealand Police.

Royal Solomon Island Police Force, 2015, Annual Report 2014, http:/www.rsipf.gov.sb/?q=system/files/RSIPFAnnualReport2014.pdf, [Accessed 7 September 2016]

Salomon, Christine. 2000. Les Femmes Kanakes face aux violence sexuelles: le tournant judiciaire des années 1990. Journale des anthropologues 82-83 pp.1-12

Salomon, Christine. 2003.Quand les filles ne se taisent plus: un aspect du changement postcolonial en Nouvelle Calédonie. Terrain: Revue d'ethnologie de l'Europe, 40 1-17.

Salomon, C. and Hamelin, C., 2010. Vers un changement des norms de genre. In E. Faugère and I. Merle (eds.) La Nouvelle Calédonie: vers in destin commun Karthala, Paris 203-224.

Schutz, A., 1944, The stranger: An essay in social psychology, American Journal of Sociology, 49(6) 499-507. 
SPC (Secretariat of the Pacific Community), 2014. Kiribati prepares to roll out legislation to protect families from domestic violence. 2 October. Available from:

http://www.spc.int/en/component/content/article/216-about-spc-news/1861-kiribati-preparesto-roll-out-legislation-to-protect-families-from-domestic-violence.html. [Accessed 4

December 2014].

SPC (Secretariat of the Pacific Community), 2009. Solomon Islands Family Health and Safety Study: A Study of Violence Against Women and Children. Noumea: SPC.

SPC (Secretariat of the Pacific Community), 2009. Kiribati Family Health and Support Study: A Study on Violence Against Women and Children. Noumea: SPC.

SPC (Secretariat of the Pacific Community), 2006. Samoa Family Health and Safety Study. Noumea: SPC.

SPC 2010. Kiribati Family Health and support Study: A study on violence against women and Children, SPC Noumea. Available from:

http//countryoffice.unfpa.org/pacific/drive/KiribatiFamilyHealthandSafetyStudy.pdf

[Accessed 14 July 2014].

SPC and UNFPA, 2001. Samoa Family Health and Safety Study, SPC Noumea. Available from:

http://countryoffice.unfpa.org/pacific/drive/SamoaFamilyHealthandSafetyStudy.pdf

[Accessed 14 July 2014]

Simmel, G, in Wolf, K., (Trans) 1950. The Sociology of Georg Simmel. New York: Free Press.

Simmel, G., 1971. The stranger, In D N Levine (ed) On Individuality and Social Forms. Chicago and London: University of Chicago Press, 143-49.

Sui, P., 1952. The Sojourner, American Journal of Sociology, 58(1): 34-44.

Skoric, M., Kisjuhas, A., Skoric, J., 2013. Excursus on 'the Stranger' in the context of Simmel’s Sociology of Space, Sociologia, 45(6): 589-602.

Stechweh, R., 1997. The Stranger - On the Sociology of Indifference, Thesis Eleven, 51:1-16.

Stonequist, E., 1937. The Marginal Man: A study of Personality and Culture Conflict, New York: Russel \& Russel.

Trnka, S., 2011. Re-mythologizing the State: Public Security, 'the Jesus Strategy' and the Fiji Police. Oceania, 81(1), 72-87.

Trujillo, M. P., \& Ross, S., 2008s. Police response to domestic violence making decisions about risk and risk management. Journal of interpersonal violence, 23(4), 454-473 
DRAFT

UNDP, 2007. Gender Sensitive Police Reform in Post Conflict Societies, United National Development Programme, New York.

van der Spuy, E., 2011, Policing beyond the domestic sphere, African Security Review, 20(4) 34-44

Vanuatu Women's Center and Vanuatu Statistics Office, 2011. Overview on Violence Against Women in Vanuatu. Available from: http://countryoffice.unfpa.org/filemanager/files/pacific/pacific_vaw/day2/2.6._vwc_meeting on_vaw_in_fiji.pdf [Accessed 2 December 2015]

White, G., 2007. Indigenous Governance in Melanesia. State Society and Governance in Melanesia, Targeted Research papers for AusAID, February.

Wood, M., 1934. The Stranger: A Study in Social Relationships, New York: Columbia University Press. 